\title{
ISPAD Clinical Practice Consensus Guidelines 2014 Compendium
}

\section{Assessment and monitoring of glycemic control in children and adolescents with diabetes}

Rewers MJ, Pillay K, de Beaufort C, Craig ME, Hanas R, Acerini CL, Maahs DM. Assessment and monitoring of glycemic control in children and adolescents with diabetes.

Pediatric Diabetes 2014: 15 (Suppl. 20): 102-114.

Marian J Rewers ${ }^{a}$, Kuben Pillay ${ }^{b}$, Carine de Beaufort ${ }^{c}$, Maria E Craig ${ }^{\mathrm{d}}$, Ragnar Hanas $^{e}$, Carlo L Acerinif and David M Maahs ${ }^{a}$

${ }^{a}$ Barbara Davis Center, University of Colorado Denver, Aurora, CO, USA; 'Westville Hospital, Durban, South Africa; 'DECCP, Clinique Pediatrique/CHL, Luxembourg, Luxembourg;

dInstitute of Endocrinology and Diabetes, Westmead, Australia; eDepartment of Pediatrics, Uddevalla Hospital, Uddevalla, Sweden and ${ }^{\mathrm{f}}$ Department of Pediatrics, University of Cambridge, Cambridge, UK

Key words: diabetes - glycemic control - ISPAD - pediatric

\author{
Corresponding author: \\ Marian J Rewers, MD, PhD, \\ Barbara Davis Center for Childhood Diabetes, \\ 1775 Aurora Court, A140, \\ Aurora, CO 80045-6511, \\ USA. \\ Tel: 303724 6838; \\ fax: 303724 6779; \\ e-mail: marian.rewers@ucdenver.edu
}

Editors of the ISPAD Clinical Practice Consensus Guidelines 2014 Compendium: Carlo Acerini, Carine de Beaufort, Maria Craig, David Maahs, Ragnar Hanas.

This article is a chapter in the ISPAD Clinical Practice Consensus Guidelines 2014 Compendium. The complete set of guidelines can be found for free download at www.ispad.org. The evidence grading system used in the ISPAD Guidelines is the same as that used by the American Diabetes Association. See page 3 (the Introduction in Pediatric Diabetes 2014; 15 (Suppl. 20): 1-3).

for comparison with stated standards to improve therapies and delivery of pediatric diabetes care (4) $(\mathrm{B} / \mathrm{C})$.

\section{Recommendations}

- To assess with accuracy and precision the level of glycemic control achieved by each individual such that they may benefit from attaining their glycemic targets $(1,2)(\mathrm{A})$.

- To help in reducing the risk of hypoglycemia, diabetic ketoacidosis (DKA), and chronic complications of microvascular and macrovascular diseases (A).

- To minimize the effect of hypoglycemia (A) and hyperglycemia $(\mathrm{B} / \mathrm{C})$ on cognitive function and $\operatorname{mood}(3)$.

- To understand determinants of glycemic control in individuals, specific patient groups, and centers,
- Self-monitoring of blood glucose (SMBG) is an childhood and adolescent diabetes and, when financially possible, should be made available for all children with diabetes (A).

- SMBG should be prescribed at a frequency to optimize each child's diabetes control, usually four to six times a day, because frequency of SMBG correlates with glycemic control (B/C).

- Blood glucose (BG) monitoring is expensive and in many countries the cost relative to the cost of living may limit this technology or make it essential tool in the optimal management of 
unavailable. However, all centers caring for young people with diabetes should urge nations, states, and health care providers to ensure that children and adolescents with diabetes have adequate BG monitoring supplies (E).

- It should be recognized that without accurate monitoring, the risks of acute crises and longterm vascular and other damaging complications are greatly increased, leading to high levels of health care costs and personal disability (A).

- Continuous glucose monitoring (CGM) devices are becoming available that may particularly benefit those with hypoglycemic unawareness, as the devices will alarm when glucose is below a specified range or with rapid rate of fall of glucose (A).

- Ketone testing should be available and performed (A):

- During illness, especially with abdominal pains, vomiting, drowsiness, or rapid breathing;

- When persistent BG levels $>14 \mathrm{mmol} / \mathrm{L}(250 \mathrm{mg} /$ $\mathrm{dL}$ ) are present.

- BG monitoring records should not be used as a judgment but as a vehicle for discussing the causes of variability and strategies for improving glycemic control (E).

- Frequent home review of records to identify patterns in glycemic levels and subsequent adjustment in diabetes management are required for successful intensified diabetes management (E).

- In some instances, especially among teenagers, maintaining written monitoring records is difficult. If the family can upload the BG monitoring data to a computer for review, this may substitute for a manual record, although details of daily management may be lost with this method (E).

- Facilities for the measurement of Hemoglobin A1c (HbA1c) should be available to all centers caring for young people with diabetes $(\mathrm{B} / \mathrm{C})$.

- Frequency of HbAlc measurement will depend on local resources, a minimum of four measurements per year is recommended $(\mathrm{B} / \mathrm{C})$.

- The target $\mathrm{HbA} 1 \mathrm{c}$ for all age-groups is recommended to be $<7.5 \%$ (B).

- Targets for all age-groups include the requirement for minimal levels of severe hypoglycemia and absence of hypoglycemia unawareness (B).

- When hypoglycemia unawareness is present, glycemic targets must be increased until hypoglycemia awareness is restored (B).

\section{General principles determining glycemic targets}

Measurement of immediate glycemic control is best determined by SMBG as this provides immediate documentation of hyperglycemia and hypoglycemia, allowing implementation of strategies to optimally treat as well as to avoid, out-of-range glucose values. CGM, available to a growing proportion of patients, enables a more comprehensive real-time monitoring that is likely to become standard in the near future.

Hemoglobin Alc (HbAlc) is the only measure of glycemic control for which robust outcome data are available. Elevated $\mathrm{HbAlc}$ predicts long-term microvascular and macrovascular outcomes $(1,2)$. The Diabetes Control and Complications Trial (DCCT), and similar studies, provide clear evidence in adults and adolescents that better metabolic control, as measured by a lower HbAlc level along with intensive management, is associated with fewer and delayed microvascular complications (1, 2, 5-7). In the DCCT, $96 \%$ of the treatment group effect on risk of complications was explained by variations in $\mathrm{HbAlc}$, although the overall effect of intensive treatment explained $<7 \%$ of the variation in the risk. Other mechanisms, on their own or through an interaction with $\mathrm{HbAlc}$, may contribute to the effect of intensive treatment on complications (8). HbAlc has limitations as a measure of glycemic control, i.e., average BG. In the DCCT, an $\mathrm{HbAlc}$ of $7.0 \%$ corresponded to a higher average BG (measured seven times a day) of $192 \mathrm{mg} / \mathrm{dL}$ $(10.7 \mathrm{mmol} / \mathrm{L})$ in the conventionally treated patients vs. $163 \mathrm{mg} / \mathrm{dL}(9.1 \mathrm{mmol} / \mathrm{L})$ in the intensively treated patients (6). Similar variability between measured BG and $\mathrm{HbAlc}$ was reported in a study that calculated average $\mathrm{BG}$ over a period of 3 months from nearcontinuous glucose sensor data ( $\geq 4 \mathrm{~d} / \mathrm{wk}$ ) (9). There was substantial individual variability, with mean sensor glucose concentrations ranging from 128 to $187 \mathrm{mg} / \mathrm{dL}$ for an $\mathrm{HbAlc}$ of $6.9-7.1 \%$. These data suggest that estimated average glucose concentrations calculated from measured $\mathrm{HbA} 1 \mathrm{c}$ values should be used with caution.

$\mathrm{HbAlc}$ is one of the several measures to assess and help achieve optimal glycemic control, along with documented hypoglycemia, type of treatment, patient's age, and quality of life. Frequent and accurate BG monitoring and concomitant optimal adjustment of insulin to carbohydrate intake and exercise are required to attain and to maintain optimal metabolic control. Finally, follow-up data from the DCCT indicate that $5-7 \mathrm{yr}$ of poor glycemic control, even during adolescence and young adulthood, results in an increased risk for microvascular and macrovascular complications in the subsequent $6-10 \mathrm{yr}(7,10-13)$. These data support trying to achieve for each individual an $\mathrm{HbAlc}$ as close to the normal range as possible.

For a comprehensive review of effects of hypoglycemia, see the Hypoglycemia section [Assessment and management of hypoglycemia in children and adolescents with diabetes]. Historically, lower HbAlc were associated with increased episodes of severe 


\section{Rewers et al.}

hypoglycemia $(1,2)$, but more recent observational studies in the era of pumps and multiple daily injections (MDI) in young people suggest this may no longer be as significant a risk as in the past (14-17). Severe hypoglycemia is a significant cause for morbidity and occasional mortality in young people with type 1 diabetes (18-21). The EURODIAB Prospective Complications Study assessed the relationship between HbAlc and all-cause 7-yr mortality among 2764 European patients with type 1 diabetes, aged 15-60 yr. The mortality risk was increased at both low and high HbA1c, following a U-shaped association. All-cause mortality risk was lowest between $\mathrm{HbAlc}$ values of $7-8 \% \quad(53.0$ and $63.9 \mathrm{mmol} / \mathrm{L})(22)$. Until the mechanisms underlying increased mortality among type 1 diabetes patients with 'normal' HbA1c are fully understood, HbAlc targets $<6.5 \%(48 \mathrm{mmol} / \mathrm{mol})$ may not be appropriate in this population.

Most, but not all, studies have shown that repeated episodes of hypoglycemic seizures in young children may cause permanent central nervous system (CNS) changes, including microstructural integrity of white matter, and/or cognitive dysfunction (23-30). In contrast, the long-term follow-up of the DCCT participants reported no evidence for permanent neurocognitive changes related to hypoglycemia in adolescent and young adult individuals (31), whereas higher HbAlc was associated with modest declines in psychomotor and mental efficiency (32). In a 3-yr longitudinal study of children aged $9-17 \mathrm{yr}$, higher HbAlc predicted worse visual, but not verbal, memory whereas severe hypoglycemia did not affect visual or verbal memory (33). The data suggests that the effect of severe hypoglycemia and chronic hyperglycemia on long-term neuropsychological functioning may be agedependent $(31,34,35)$. Regardless of the long-term sequelae of hypoglycemia, the fear of hypoglycemia has been shown to cause intentional decreases in insulin dosing, resulting in elevated glucose levels and increased HbAlc (36).

Importantly, there is evidence that chronic hyperglycemia (particularly in young boys) might be related to poorer neurocognitive outcomes (37). Acute hyperglycemia (BG $>15 \mathrm{mmol} / \mathrm{L}, \quad 270 \mathrm{mg} / \mathrm{dL})$ was associated with reduced motor cognitive performance in adults with type 1 diabetes (38), confirming findings of reduced performance in children at $\mathrm{BG}>20 \mathrm{mmol} / \mathrm{L}$ $(360 \mathrm{mg} / \mathrm{dL})$ compared with $5-10 \mathrm{mmol} / \mathrm{L}$ (90-180 $\mathrm{mg} / \mathrm{dL}$ ) (39). Families report effects of hyperglycemia $(15-18 \mathrm{mmol} / \mathrm{L}, \quad 270-324 \mathrm{mg} / \mathrm{dL})$ on $\operatorname{mood}$ and coordination (40). Long-term studies on hyperglycemia and cognitive functioning are not available. Existing evidence has been reviewed $(41,42)$.

Brain imaging studies show that both hypoglycemia and hyperglycemia cause changes in the white and gray matter of developing brains (43). There is evidence for
CNS changes in children with diabetes associated with hyperglycemia as well as hypoglycemia, although the cognitive functioning and brain imaging findings in children with diabetes as a whole are not significantly different from healthy control children $(43,44)$. The CNS changes in association with hyperglycemia are relatively new findings $(3,34,41,45,46)$, but are consistent with reported neurocognitive findings (37). One theory is that chronic hyperglycemia during the early years before age $5 \mathrm{yr}$, when the brain is still developing, will affect it negatively with white matter dysfunction due to a non-optimal myelinization. This makes the brain more vulnerable to any subsequent insult, including hypoglycemia, which occurs later in the child's life (47). There is also evidence that fluctuation in glucose levels is more harmful than sustained hyperglycemia or hypoglycemia (48).

At present, the safest recommendation for improving glycemic control generally in all children is to achieve the lowest HbAlc that can be sustained without disabling or severe hypoglycemia while avoiding prolonged periods of significant hyperglycemia (38-40) and episodes of DKA. Frequent glucose monitoring is necessary for these goals to be achieved while maintaining acceptable quality of life.

\section{Monitoring of glycemic control - SMBG}

- helps to monitor immediate and daily levels of BG control;

- helps to determine immediate and daily basal and bolus insulin requirements;

- helps guide insulin adjustments to decrease fluctuations in BG levels;

- detects hypoglycemia and assists in its management; and

- assists in the safe management of hyperglycemia.

The frequency of SMBG is associated with improved $\mathrm{HbAlc}$ in patients with type 1 diabetes (49-56). This is thought to be because of both better insulin adjustment for food consumed and an improved ability to quickly correct out-of-target glucose values. In addition, early detection of lower glucose values prior to symptomatic hypoglycemia may allow correction with a decreased risk of overcorrection and resultant hyperglycemia. The use of SMBG during exercise may also allow improved insulin management and a decreased risk for hypoglycemia during and following exercise (57).

Patient acceptance of SMBG may be enhanced by including the opportunity for testing alternative sites in addition to the fingertips, e.g., the palm of the hand or the forearm. In the fasting state, glucose readings from the forearm are similar to the fingertip (58). These alternative sites may be slower to reflect falling $\mathrm{BG}$ levels, so it is advised that fingertips are used when 
symptoms of hypoglycemia are present and to recheck the glucose using the fingertip if the alternative site test is in a low range (59).

\section{Equipment}

There are many types of excellent monitors for SMBG; however, significant inaccuracy may arise from operator-related errors (60). Health care professionals should choose and advise on a type that is robust, precise, accurate, and familiar to them as well as affordable to the patient. Low quality devices, offered sometimes to reduce cost, may compromise patient safety. High industry standards, including accuracy, precision, and ability to download and analyze data should be upheld by the regulatory agencies. New industry standards state that $95 \%$ of readings should be within $\pm 15 \%$ of the reference value.

\section{Timing of SMBG}

BG is best measured:

- at bedtime, during the night and after the overnight fast to detect and prevent nocturnal hypoglycemia and hyperglycemia as well as optimize basal insulin;

- during the day, prior to meals and after food intake ( $2 \mathrm{~h}$ after a meal). To help determine meal insulin doses and to show levels of BG in response to the action profiles of insulin (at anticipated peaks and troughs of insulin action).

- In association with vigorous exercise (prior to, during, and several hours after) such that changes may be made in management of glycemia $(56,61$, 62);

- prior to driving a car or operating similar machinery;

- to confirm hypoglycemia and to monitor recovery; and

- during intercurrent illness to prevent hyperglycemic crises.

The number and regularity of SMBG should be individualized depending on:

- availability of equipment;

- type of insulin regimen;

- ability of the child to identify hypoglycemia;

- the cost of SMBG testing in resource-poor settings.

Note: Successful application of intensified diabetes management with multiple injection therapy or insulin infusion therapy requires frequent SMBG (four to six times a day) and regular, frequent review of the results to identify patterns requiring adjustment to the diabetes treatment plan. This includes review by patients and their families in addition to consultation with the diabetes care team.

\section{Targets}

The targets are intended as guidelines (Table 1). There is little scientific evidence for age-related glucose targets. Each child should have their targets individually determined with the goal of achieving a value as close to normal as possible while avoiding severe hypoglycemia, as well as frequent mild to moderate hypoglycemia. In patients beyond partial remission phase, the rule of thumb is to strive for at least $50 \%$ of BGs in range, e.g., $70-180 \mathrm{mg} / \mathrm{dL}$ (3.9-10 $\mathrm{mmol} / \mathrm{L})$, and $<10 \%$ below the range.

\section{Continuous glucose monitoring (CGM)}

Minimally invasive devices are available that measure subcutaneous interstitial fluid glucose every $1-5 \mathrm{~min}$, i.e., 'continuously'. CGM may particularly benefit those with hypoglycemic unawareness, as the devices will alarm when glucose is below a specified range or with rapid rate of fall of glucose (63-68). All devices allow targets to be set so that an alarm will alert the wearer to a glucose value projected to fall below or above the target in 10-30 min, based on the rate of change of the interstitial glucose (69). CGM can also identify times of consistent hyperglycemia and times of increased risk for hypoglycemia presenting a much more sophisticated approach to home SMBG. Days with outlier glucose values can also be more readily identified. With short-term use of sensors, mean BG values decrease and time spent in the hypoglycemic range also decreases $(70,71)$.

Availability of CGM results in real-time to the patient or adult guardian and immediate corrections to keep BG in range have been shown to improve glycemic control more effectively than 'blinded' collection of data analyzed by a health provider at a later time (72). It is currently recommended that CGM values are confirmed by standard SMBG for real-time adjustments of insulin dosing, at least early in CGM use. However, periodic downloads allow the patient and health provider to review a larger amount of data and make more comprehensive adjustments. The review of the CGM results is a very helpful teaching tool for the effects of food, insulin timing, and exercise on glucose levels. The intermittent, delayed readout has been helpful in diagnosis and management of hyperglycemia in special groups of patients, e.g., those with pre-type 1 diabetes (73), monogenic diabetes (74), or cystic fibrosis-related diabetes (CFRD) $(75,76)$. Information gained from CGM studies has provided information that allows improved recommendations for insulin management for all individuals with diabetes (77-80), including those not using continuous sensing devices.

Current limitations of CGM include economic and behavioral barriers and still imperfect accuracy of some 
Rewers et al.

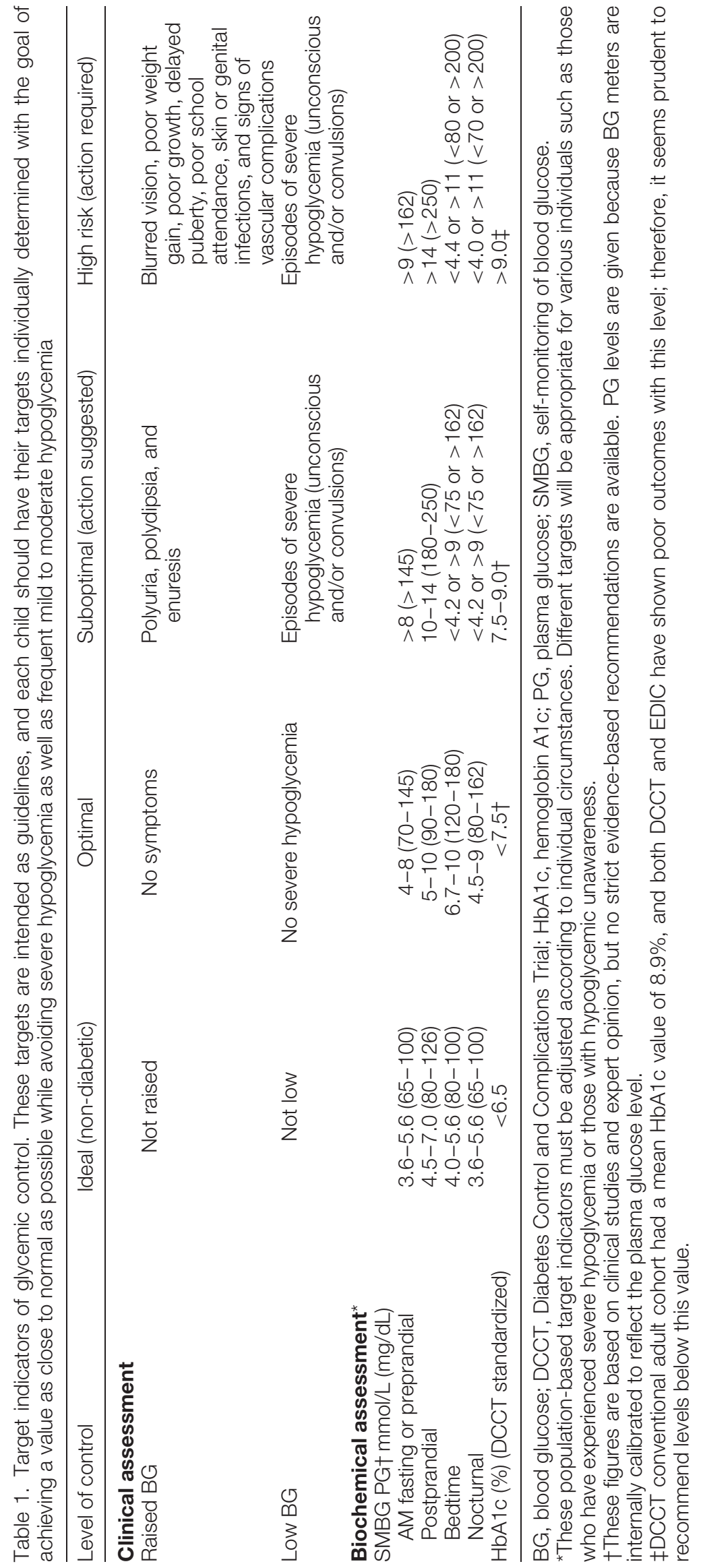


sensors that may discourage patients from routine use. Currently, these devices, while approved for pediatric use, are expensive and may not be available in many countries. Insurance coverage is also limited outside USA. Over time, these devices will likely become more widely available and, with greater evidence of efficacy, may be covered by both national and private insurance. While CGM is beneficial in both patients using MDI and insulin pump users, the latter combination is more effective (81). Studies of longer-term CGM use (6 months) have found that, despite benefiting from similar reduction in $\mathrm{HbAlc}$, children and adolescents may not be willing to wear a device as often, or for as prolonged a period of time as is required to result in consistently improved glucose metabolism (82). Not surprisingly, the frequency of sensor use predicts the HbAlc-lowering effect of the sensor $(83,84)$. These results indicate additional work is needed to develop technology that is less intrusive in a teen's life and to identify ways to help adolescents adapt to health care tasks required to maintain optimal, near-normal glucose levels. Early experience, with sensors of less than perfect accuracy, may discourage some users from long-term change (85); this is likely to change with the observed rapid improvement in sensor technology and patient retraining. With more widespread use of CGM, decreased BG targets could be safely achieved, improving outlook for children with diabetes $(64,66,86)$.

Technological advances in continuous subcutaneous insulin infusion (CSII) and CGM has led to the development of pumps that adjust insulin delivery based on ambient BG and computerized algorithms (artificial pancreas). Such devices reduce the risk of severe and moderate hypoglycemia, particularly overnight $(14,87-89)$ and hold promise to reduce the burden of care and improve glucose control (90).

\section{Monitoring of urinary or blood ketones}

- Urine or blood ketones measurement should be monitored during episodes of uncontrolled hyperglycemia, insulin deficiency, intercurrent illness (sick days), and impending ketoacidosis,

- especially with abdominal pains, vomiting, drowsiness, or rapid breathing.

- when persistent BG levels >14 mmol/L (250 mg/ $\mathrm{dL}$ ) are present.

- Blood beta-hydroxybutyrate ( $\beta$-OHB) determination has been shown to be more effective than urine ketone determinations in reducing emergency room visits, hospitalization rates, and time to recovery from DKA (91-93).

- Blood $\beta-\mathrm{OHB}$ testing is especially recommended if a urine sample is difficult to obtain, in a young child, in insulin pump users (who do not have a long-acting insulin depot) and in patients with a history of prior episodes of DKA (94).

The correlation between interquartile range of capillary blood $\beta$-OHB and urinary ketone reading (95):

- $0.1-0.9 \mathrm{mmol} / \mathrm{L}$ blood $\beta$-OHB corresponds to + or 'small' urinary ketones;

- $0.2-1.8 \mathrm{mmol} / \mathrm{L}$ blood $\beta$-OHB corresponds to ++ or 'moderate' urinary ketones;

- $1.4-5.2 \mathrm{mmol} / \mathrm{L}$ blood $\beta$-OHB corresponds to +++ or 'large' urinary ketones.

\section{Equipment for urinary ketone determination}

- Tablets or urine testing strips for ketone testing are available, which detect increased levels of urinary acetoacetate (Note: $\beta$-OHB not acetoacetate is the major blood ketone).

\section{Interpretation of urine ketone testing}

Moderate or large urinary ketone levels in the presence of hyperglycemia indicate insulin deficiency and risk for metabolic decompensation leading to ketoacidosis. The presence of vomiting or labored breathing with hyperglycemia and large urinary ketones must be assumed to be because of systemic acidosis and requires further evaluation. Urine ketone testing is less specific for ruling out or diagnosing DKA than blood $\beta-\mathrm{OHB}$ testing.

\section{Equipment for blood ketone determination}

- Meters are available for blood $\beta-O H B$ testing and can also be used for capillary BG testing (two different strips).

- Determination of blood $\beta$-OHB levels can guide management, e.g., if oral fluid therapy can be safely continued or if more intensive treatment is required to avert severe ketoacidosis $(92,94)$. There is a close correlation between venous $\mathrm{pH}$ and blood ketone level (92).

\section{Interpretation of blood $\beta$-OHB testing}

- $<0.6 \mathrm{mmol} / \mathrm{L}$ is normal, and no action is needed.

- $0.6-1.5 \mathrm{mmol} / \mathrm{L}$ is somewhat elevated, but usually responds quickly to oral fluids containing carbohydrate if $\mathrm{BG}$ is $<10 \mathrm{mmol} / \mathrm{L}(180 \mathrm{mg} / \mathrm{dL})$. Give additional subcutaneous injection of a rapid-acting insulin if $\mathrm{BG}$ is elevated $>10 \mathrm{mmol} / \mathrm{L}(180 \mathrm{mg} / \mathrm{dL})$.

- $1.5-3.0 \mathrm{mmol} / \mathrm{L}$ marks high risk of ketoacidosis, but usually can be managed with oral fluids and subcutaneous injection of a rapid-acting insulin. Diabetes provider or Emergency Department (ED) should be consulted. 


\section{Rewers et al.}

- $>3.0 \mathrm{mmol} / \mathrm{L}$ is usually accompanied by acidosis. Urgent contact with diabetes provider or ED is needed.

BG levels must be checked before administering insulin in patients with ketonuria or ketosis. Urine or blood ketones may be elevated in diabetic patients as a physiological metabolic response to fasting, low carbohydrate diets (e.g., Atkins diet), during prolonged exercise, or pregnancy as well as in gastroenteritis and in alcohol intoxication. BG levels are normal or low in these situations, and supplemental insulin is not indicated. To correct the metabolic 'starvation', electrolyte-containing fluids with low glucose content (e.g., Gatorade, Pedialyte, and Poweraid) may be used when BG levels are $150-250 \mathrm{mg} / \mathrm{dL}(8.5-14 \mathrm{mmol} / \mathrm{L})$. The sugar content of the fluid should be increased further when $B G$ is $<150 \mathrm{mg} / \mathrm{dL} \quad(8.5 \mathrm{mmol} / \mathrm{L})$. However, if $\beta-\mathrm{OHB}$ is $>1.0 \mathrm{mmol} / \mathrm{L}$, extra insulin is needed, once the BG level has risen after giving extra carbohydrate. See ISPAD guidelines for Sick Day Management for more detailed advice.

\section{Record keeping of glycemic control}

- It is common practice for a monitoring diary, logbook, spreadsheet, smart BG meter, or app to be used to record patterns of glycemic control and adjustments to treatment. This BG information along with insulin doses should be reviewed by patients and families regularly.

- The record book or data from the electronic device is useful at the time of consultation and should contain time and date of:

- BG levels;

- insulin dosage;

- note of special events affecting glycemic control (e.g., illness, parties, exercise, menses).

- carbohydrate intake (for smart meters);

- hypoglycemic episodes, description of severity, and potential alterations in the usual routine to help explain the cause for the event; and

- episodes of ketonuria/ketonemia.

- Monitoring records should not be used as a judgment but as a vehicle for discussing the causes of variability and strategies for improving glycemic control.

- Frequent home review of records by the patient and their caregivers to identify patterns in glycemic levels and subsequent adjustment in diabetes management are required for successful intensified diabetes management.

- In some instances, especially among teenagers, maintaining written monitoring records is difficult.
If the family has access to a computer and can upload the BG monitoring data for review, this may substitute for a manual record, although details of management may be lost with this method.

\section{Glycated hemoglobin}

- Glucose becomes irreversibly attached to the molecule of hemoglobin during the life cycle of the circulating red cell (which is approximately $120 \mathrm{~d}$ ) forming glycated hemoglobin ( $\mathrm{HbA} 1$ or $\mathrm{HbAlc}$ ).

- HbAlc reflects levels of glycemia over the preceding 4-12 wk, weighted toward the most recent $4 \mathrm{wk}$. However, the most recent week is not included because the most recent glycation is reversible (96). HbA1c monitoring has been shown to be the most useful measure in evaluating metabolic control and is the only measure for which good data are available in terms of its relationship with later microvascular and macrovascular complications $(1,2)$.

The development of the HbA1c assay revolutionized diabetes management and provided an objective, long-term measure of glycemia. There is a distinct relationship between $\mathrm{HbA1c}$ and BG (97). However, there are disparities between the relationship of $\mathrm{HbAlc}$ and average $\mathrm{BG}$ with $\mathrm{HbAlc}$ assays (98). Standardization of HbAlc assays and a better understanding of the relationship of HbAlc measurements to average $\mathrm{BG}$ are a necessary next step in improving diabetes care $(99,100)$. The International Federation of Clinical Chemistry (IFCC) developed a new reference method that precisely measures the concentration of glycated HbA1c only $(101,102)$. The reference measurement procedure has been defined as $\beta$ N1-deoxyfructosylhemoglobin, and the recommended SI measurement units are $\mathrm{mmol} / \mathrm{mol}(102,103)$. IFFC/ADA (American Diabetes Association)/EASD (European Association for the Study of Diabetes)/IDF (International Diabetes Federation) has issued a consensus statement regarding this standardization process (104). A calculator for conversion between the DCCT/NGSP (National Glycohemoglobin Standardization Program) \% units and the IFCC/SI mmol/mol units can be found at http://www.ngsp.org/convert1.asp

\section{Equipment and facilities}

- A normal reference range for non-diabetic children should be available.

- There should be regular quality control comparisons with national and DCCT or IFCC standards. It is recommended that scientific papers provide HbAlc in both DCCT/NGSP and IFCC/SI numbers. 
- It is preferable that a capillary method for collection of the child's blood is available and that the HbA1c result is available at the time of the medical visit such that immediate adjustments in management can be based on the HbAlc level. A rapid method using a prepared kit has been shown to provide results comparable to chromatographic methods (105).

- Facilities for the measurement of HbA1c should be available to all centers caring for young people with diabetes. Frequency of measurement will depend on local facilities and availability.

- Every child should have a minimum of four measurements per year.

\section{HbA1c targets}

A target of $<7.5 \% \quad(58 \mathrm{mmol} / \mathrm{mol})$ is recommended for all patients younger than $18 \mathrm{yr}$ (Table 1). Of note, the American Diabetes Association has recently adopted the same target (106), acknowledging that there is little scientific evidence for age-related A1c targets within pediatric population. This target is intended as an aspirational goal, with the recognition that vast majority of children and adolescents currently do not meet it. For instance, in USA, only $27 \%$ of children younger than 13 and $23 \%$ of those between 13 and $19 \mathrm{yr}$ of age meet this goal (107). On the other hand, in Sweden, $60 \%$ of those younger than 13 and $36 \%$ of youth between 13 and 18 -yr had A1c $<7.5 \%$ in 2013 (108). Each child should have their targets individually determined with the goal of achieving a value as close to normal as possible while avoiding severe hypoglycemia as well as frequent mild to moderate hypoglycemia.

The goal is to avoid the long-term microvascular and macrovascular complications of diabetes while also avoiding sequelae of acute hypoglycemia and the CNS changes associated with both hypoglycemia and hyperglycemia. Evidence from the DCCT is available for adolescents, and recommendations for younger children can only be determined using these data and expert opinion. The intensively treated adolescent cohort of the DCCT achieved a mean $\mathrm{HbAlc}$ of $8.1 \%(65 \mathrm{mmol} / \mathrm{mol})$, whereas subjects in the corresponding adult cohort achieved a mean $\mathrm{HbAlc}$ of $7.1 \%$ (54 mmol/mol). Subjects in the followup observational study, Epidemiology of Diabetes Interventions and Complications (EDIC), maintained an average $\mathrm{HbAlc}$ of $7.8-8.2 \%(62-66 \mathrm{mmol} / \mathrm{mol})$ regardless of DCCT randomization, during the $30 \mathrm{yr}$ of follow-up reported to date $(13,109)$. In addition, a proportion of children should expect to achieve an HbAlc within the normal reference range at some time in the first year after diagnosis (during the partial remission phase), generally between 1 and 6 months after diagnosis.
In many studies, there is evidence of an increased risk for hypoglycemia as the HbAlc decreases $(1,2$, $110,111)$, but this is not always the case $(4,53,112)$, particularly in recent years with the increasing use of insulin analogs and CSII (14-17). Glycemic control and the risk of hypoglycemia may be decreased by the choice of insulin regimens and the frequency of $\mathrm{BG}$ monitoring. Targets for $\mathrm{HbAlc}$ are given with the expectation that careful attention will be taken to avoid severe hypoglycemia. Because severe hypoglycemia is more common when hypoglycemia unawareness is present, HbAlc targets must be increased when hypoglycemia unawareness occurs.

- In non-diabetic individuals, counterregulatory systems are normally activated at a BG level of $3.6-3.9 \mathrm{mmol} / \mathrm{L}(65-70 \mathrm{mg} / \mathrm{dL})$, whereas symptoms of hypoglycemia occur at a BG of approximately $<3.2-3.6 \mathrm{mmol} / \mathrm{L}(58-65 \mathrm{mg} / \mathrm{dL})$ and cognitive dysfunction increases as BG decreases $(113,114)$.

- Asymptomatic hypoglycemia in persons with diabetes is defined as the occurrence of a plasma glucose value $<3.9 \mathrm{mmol} / \mathrm{L}(70 \mathrm{mg} / \mathrm{dL})$ without signs or symptoms of adrenergic release. BG below this level reduces sympathoadrenal responses to subsequent hypoglycemia $(115,116)$.

- Hypoglycemia unawareness is defined as neuroglycopenia occurring before autonomic activation and can be associated with reduced awareness of the onset of hypoglycemia (117).

- It occurs when a single, or multiple, hypoglycemic episode(s) lead to a significant decrease in neurohormonal counterregulatory responses causing unawareness of hypoglycemia (118).

- Hypoglycemia unawareness is more common in those who maintain generally lower BG levels (119, 120).

- CGM devices are becoming more available and may particularly benefit those with hypoglycemic unawareness, as the devices will alarm when glucose is below a specified range or with rapid rate of fall of glucose $(63,64,87)$.

- There is evidence that loss of awareness of hypoglycemia can be reversed by avoiding hypoglycemia for $2-3 \mathrm{wk}(120,121)$, although this is difficult for very young patients.

- Individuals and families should be instructed in the signs and symptoms of hypoglycemia unawareness, and a history for hypoglycemia unawareness should be taken at every diabetes care visit.

The youngest children $(<6 \mathrm{yr})$ are at increased risk for adverse neurologic outcomes from severe hypoglycemia, and because they are unable to selfidentify hypoglycemia, caution in achieving lower targets for younger children is appropriate (122, 


\section{Rewers et al.}

123). In reality, many pediatric centers find that the average $\mathrm{HbAlc}$ is in fact lowest in this youngest age-group, reflecting the more complete caregiver involvement at younger ages. The Diabetes Patienten Verlaufsdokumentation (DPV) registry reported a mean $\mathrm{HbA} 1 \mathrm{c}$ of $7.4 \%$ in contrast to the Type 1 Diabetes Exchange mean of $8.2 \%$ with no difference in reported severe hypoglycemia suggesting that a target of $<7.5 \%$ can be achieved safely in this age-group (124).

As teens approach adulthood, targets similar to those of the adult population should be approached $(<7 \%)$, recognizing that the hormonal alterations and psychological adjustments of adolescence make achieving these targets difficult. Of all age-groups, adolescents are currently the farthest from achieving $\mathrm{HbA} 1 \mathrm{c}<7.5 \%$ (107), reflecting the diabetes mismanagement that frequently accompanies the increased independence in diabetes care during the adolescent years, as well as the effect of psychological and hormonal challenges of adolescence. However, results from the DCCT and the follow-up EDIC studies document that poor control for 5-7 yr, which is similar to the duration of puberty, may have prolonged adverse effects $(7,10-13)$. While better insulins, insulin pumps, and glucose monitors are available today, compared with the DCCT era, adolescents in general may still be unable to achieve a lower HbA1c levels than the DCCT adolescent average without novel approaches to care in this age-group. Too ambitious goals may lead to an unwarranted sense of failure and alienation on part of many teenage patients.

As diabetes technology improves, especially CGM, recommended target indicators for glycemic control will likely decrease to reflect a new balance of benefits and risks.

\section{Health care priorities}

Care providers should be aware that achieving an HbAlc consistently below the target range without extensive personal and national health care resources and outside of a clinical trial structure may be very difficult. As a benchmark, the most recent mean $\mathrm{HbAlc}$ is $7.8 \%(62 \mathrm{mmol} / \mathrm{mol})$ in a well-educated EDIC cohort that has excellent access to the newest diabetes technology and a mean age of $45 \pm 7 \mathrm{yr}(13,109)$.

\section{Fructosamine and other glycated products}

Fructosamine measures the glycation of serum proteins such as albumin and reflects glycemia over the preceding 3-4 wk. It is therefore used for the assessment of shorter periods of control than HbAlc. Fructosamine or glycated albumin may be useful in monitoring glucose control over time in individuals with abnormal red cell survival time. Fructosamine and other glycated products have been recently evaluated in terms predicting development of vascular complications. In DCCT/EDIC, glycated albumin and HbAlc had similar associations with retinopathy and nephropathy, which were strengthened when both measures were considered together. Only $\mathrm{HbAlc}$ was significantly associated with development of cardiovascular disease (CVD) (125). In the Atherosclerosis Risk in Communities (ARIC) study that included adults with type 1 and 2 diabetes, fructosamine and glycated albumin were associated with microvascular complications, with prognostic value comparable to HbAlc (126).

\section{Conflicts of interest}

The authors have declared no conflicts of interest.

\section{References}

1. DCCT Research Group (Diabetes Control and Complications Trial Research Group). The effect of intensive treatment of diabetes on the development and progression of long-term complications in insulindependent diabetes mellitus. N Engl J Med 1993: 329: 977-986.

2. DCCT Research Group (Diabetes Control and Complications Trial Research Group). Effect of intensive diabetes treatment on the development and progression of long-term complications in adolescents with insulin-dependent diabetes mellitus: Diabetes Control and Complications Trial. J Pediatr 1994: 125: 177-188.

3. Arbelaez AM, Semenkovich K, Hershey T. Glycemic extremes in youth with T1DM: the structural and functional integrity of the developing brain. Pediatr Diabetes 2013: 14: 541-553.

4. de Beaufort CE, Swift PG, Skinner CT et al. Continuing stability of center differences in pediatric diabetes care: do advances in diabetes treatment improve outcome? The Hvidoere Study Group on childhood diabetes. Diabetes Care 2007: 30: 2245-2250.

5. Nathan DM, Zinman B, Cleary PA et al. Modernday clinical course of type 1 diabetes mellitus after 30 years' duration: the diabetes control and complications trial/epidemiology of diabetes interventions and complications and Pittsburgh epidemiology of diabetes complications experience (1983-2005). Arch Intern Med 2009: 169: 1307-1316.

6. White NH, Cleary PA, Dahms W, Goldstein D, Malone J, TAmborlane WV. Beneficial effects of intensive therapy of diabetes during adolescence: outcomes after the conclusion of the Diabetes Control and Complications Trial (DCCT). J Pediatr 2001: 139: 804-812.

7. Mohsin F, Craig ME, Cusumano J et al. Discordant trends in microvascular complications in adolescents with type 1 diabetes from 1990 to 2002. Diabetes Care 2005: 28: 1974-1980. 
8. Lachin JM, Genuth S, Nathan DM, Zinman B, RutLEDGE BN. Effect of glycemic exposure on the risk of microvascular complications in the Diabetes control and complications trial--revisited. Diabetes 2008: 57: 995-1001.

9. Wilson DM, Xing D, Beck RW et al. Hemoglobin $\mathrm{A}_{1 \mathrm{c}}$ and mean glucose in patients with type 1 diabetes analysis of data from the Juvenile Diabetes Research Foundation continuous glucose monitoring randomized trial. Diabetes Care 2011: 34: 540-544.

10. DiLiberti JH, Lorenz RA. Long-term trends in childhood diabetes mortality: 1968-1998. Diabetes Care 2001: 24: 1348-1352.

11. Donaghue KC, Fung AT, Hing $\mathrm{S}$ et al. The effect of prepubertal diabetes duration on diabetes. Microvascular complications in early and late adolescence. Diabetes Care 1997: 20: 77-80.

12. Writing Team for the DCCT/EDIC Research Group. Sustained effect of intensive treatment of type 1 diabetes mellitus on development and progression of diabetic nephropathy: the Epidemiology of Diabetes Interventions and Complications (EDIC) study. JAMA 2003: 290: 2159-2167.

13. Orchard TJ, Forrest KY, Kuller LH, Bercker DJ. Lipid and blood pressure treatment goals for type 1 diabetes: 10-year incidence data from the Pittsburg Epidemiology of Diabetes Complications Study. Diabetes Care 2001: 24: 1053-1059.

14. Ly TT, Nicholas JA, Retterath A, Lim EM, Davis EA, JONES TW. Effect of sensor-augmented pump therapy and automated insulin suspension vs standard insulin pump therapy on hypoglycemia in patients with type 1 diabetes: a randomized clinical trial. JAMA 2013: 310: 1240-1247.

15. Johnson SR, Cooper MN, Jones TW, Davis EA. Long-term outcome of insulin pump therapy in children with type 1 diabetes assessed in a large population-based case-control study. Diabetologia 2013: 56: 2392-2400.

16. Downie E, Craig Me, Hing S, Cusumano J, Chan AK, Donaghue KC. Continued reduction in the prevalence of retinopathy in adolescents with type 1 diabetes: role of insulin therapy and glycemic control. Diabetes Care 2011: 34: 2368-2373.

17. Cooper MN, O'Connell SM, DAvis EA, Jones TW. A population-based study of risk factors for severe hypoglycaemia in a contemporary cohort of childhood-onset type 1 diabetes. Diabetologia 2013: 56: $2164-2170$.

18. Secrest AM, Becker DJ, Kelsey SF, LaPorte RE, ORCHARD TJ. Characterizing sudden death and deadin-bed syndrome in type 1 diabetes: analysis from two childhood-onset type 1 diabetes registries. Diabet Med 2011: 28: 293-300.

19. Weston PJ, GiLl GV. Is undetected autonomic dysfunction responsible for sudden death in type 1 diabetes mellitus? The 'dead in bed' syndrome revisited. Diabet Med 1999: 16: 626-631.

20. Sovik O, Thordarson H. Dead-in-bed syndrome in young diabetic patients. Diabetes Care 1999: 22 (Suppl 2): B40-B42.

21. Nishimura R, LaPorte RE, Dorman JS, Tajima N, Becker D, Orchard TJ. Mortality trends in type
1 diabetes. The Allegheny County (Pennsylvania) Registry 1965-1999. Diabetes Care 2001: 24: 823-827.

22. Schoenaker DA, Simon D, Chaturvedi N, Fuller JH, Soedamah-Muthu SS. Glycemic control and allcause mortality in type 1 diabetes patients: the EURODIAB Prospective Complications Study. J Clin Endocrinol Metab 2014: 99: 800-807.

23. Austin EJ, DeAry IJ. Effects of repeated hypoglycemia on cognitive function: a psychometrically validated reanalysis of the Diabetes Control and Complications Trial data. Diabetes Care 1999: 22: 1273-1277.

24. Wysocki T, Harris MA, Mauras N et al. Absence of adverse effects of severe hypoglycemia on cognitive function in school-aged children with diabetes over 18 months. Diabetes Care 2003: 26: 1100-1105.

25. DAvis EA, Jones TW. Hypoglycemia in children with diabetes: incidence, counterregulation and cognitive dysfunction. J Pediatr Endocrinol Metab 1998: 11 (Suppl 1): 177-182.

26. Strudwick SK, Carne C, Gardiner J, Foster JK, Davis EA, Jones TW. Cognitive functioning in children with early onset type 1 diabetes and severe hypoglycemia. J Pediatr 2005: 147: 680-685.

27. Soltesz G, Acsadi G. Association between diabetes, severe hypoglycaemia, and electroencephalographic abnormalities. Arch Dis Child 1989: 64: 992-996.

28. SChlaCK H, Palm D, Jochmus I. Influence of recurrent hypoglycemia on the EEG of the diabetic child. Monatsschr Kinderheilkd 1969: 117: 251-253.

29. Ryan CM, Williams TM, Finegold DN, Orchard TJ. Cognitive disfunction in adults with type 1 (insulin-dependent) diabetes mellitus of long duration: effects of recurrent hypoglycemia and other chronic complications. Diabetologia 1993: 36: 329-334.

30. Gilhaus KH, Daweke H, Lulsdorf HG, Sachsse R, SACHSSE B. EEG changes in diabetic children. Dtsch Med Wochenschr 1973: 98: 1449-1454.

31. Jacobson AM, Musen G, Ryan CM et al. Longterm effect of diabetes and its treatment on cognitive function. New England Journal of Medicine 2007: 356: $1842-1852$.

32. Musen G, JaCOBSON AM, Ryan CM et al. Impact of diabetes and its treatment on cognitive function among adolescents who participated in the Diabetes Control and Complications Trial. Diabetes Care 2008: 31: $1933-1938$.

33. Kent S, Chen R, Kumar A, Holmes C. Individual growth curve modeling of specific risk factors and memory in youth with type 1 diabetes: an accelerated longitudinal design. Child Neuropsychol 2009: 16: $169-181$.

34. Antenor-Dorsey JA, Meyer E, Rutlin J et al. White matter microstructural integrity in youth with type 1 diabetes. Diabetes 2013: 62: 581-589.

35. Tupola S, Rajantie J, Akerblom HK. Experience of severe hypoglycaemia may influence both patient's and physician's subsequent treatment policy of insulindependent diabetes mellitus. Eur J Pediatr 1998: 157: 625-627.

36. Schoenle EJ, Schoenle D, Molinari L, Largo RH. Impaired intellectual development in children with type I diabetes: association with $\mathrm{HbA}(1 \mathrm{c})$, age at diagnosis and sex. Diabetologia 2002: 45: 108-114. 
37. Cox DJ, Kovatchev BP, Gonder-Frederick LA et al. Relationships between hyperglycemia and cognitive performance among adults with type 1 and type 2 diabetes. Diabetes Care 2005: 28: 71-77.

38. Davis EA, Soong SA, Byrne GC, Jones TW. Acute hyperglycaemia impairs cognitive function in children with IDDM. J Pediatr Endocrinol Metab 1996: 9: 455-461.

39. Martin DD, Davis EA, Jones TW. Acute effects of hyperglycemia in children with type 1 diabetes mellitus: the patient's perspective. J Pediatr Endocrinol Metab 2006: 19: 927-936.

40. Perantie DC, Wu J, Koller JM et al. Regional brain volume differences associated with hyperglycemia and severe hypoglycemia in youth with type 1 diabetes. Diabetes Care 2007: 30: 2331-2337.

41. Barnea-Goraly N, Raman M, Mazaika P et al. Alterations in white matter structure in young children with type 1 diabetes. Diabetes Care 2014: 37: 332-340.

42. Gaudieri PA, Chen R, Greer TF, Holmes CS. Cognitive function in children with type 1 diabetes: a meta-analysis. Diabetes Care 2008: 31: 1892-1897.

43. Musen G, Lyoo IK, Sparks CR et al. Effects of type 1 diabetes on gray matter density as measured by voxelbased morphometry. Diabetes 2006: 55: 326-333.

44. Ryan CM. Why is cognitive dysfunction associated with the development of diabetes early in life? The diathesis hypothesis. Pediatr Diabetes 2006: 7: 289-297.

45. Marzelli MJ, Mazaika PK, Barnea-Goraly N et al. Neuroanatomical correlates of dysglycemia in young children with type 1 diabetes. Diabetes 2014: 63: $343-353$.

46. Kirchioff BA, Lugar HM, SMith SE et al. Hypoglycaemia-induced changes in regional brain volume and memory function. Diabet Med 2013: 30: e151-e156.

47. Schiffrin A, Belmonte M. Multiple daily self-glucose monitoring: its essential role in long-term glucose control in insulin-dependent diabetic patients treated with pump and multiple subcutaneous injections. Diabetes Care 1982: 5: 479-484.

48. Russo VC, Higgins S, Wether GA, Cameron FJ. Effects of fluctuating glucose levels on neuronal cells in vitro. Neurochem Res 2012: 37: 1768-1782.

49. Svoren BM, Volkening LK, Butler DA, Moreland EC, Anderson BJ, Laffel LM. Temporal trends in the treatment of pediatric type 1 diabetes and impact on acute outcomes. J Pediatr 2007: 144: 660-661.

50. Nathan DM, Lachin J, Cleary P et al. Intensive diabetes therapy and carotid intima-media thickness in type 1 diabetes mellitus. N Engl J Med 2003: 348: 2294-2303.

51. Haller MJ, Stalvey MS, Silverstein JH. Predictors of control of diabetes: monitoring may be the key. $\mathrm{J}$ Pediatr 2004: 144: 660-661.

52. Levine BS, Anderson BJ, Butler DA, Antisdel JE, Brackett J, LAfFel LM. Predictors of glycemic control and short-term adverse outcomes in youth with type 1 diabetes. J Pediatr 2001: 139: 197-203.

53. Plotnick LP, Clark LM, Brancati FL, Erlinger T. Safety and effectiveness of insulin pump therapy in children and adolescents with type 1 diabetes. Diabetes Care 2003: 26: 1142-1146.
54. Schneider S, IAnnotti RJ, Nansel TR et al. Identification of distinct self-management styles of adolescents with type 1 diabetes. Diabetes Care 2007: 30: $1107-1112$.

55. Weinzimer SA, Ahern JH, Doyle EA et al. Persistence of benefits of continuous subcutaneous insulin infusion in very young children with type 1 diabetes: a follow-up report. Pediatrics 2004: 114: 1601-1605.

56. Tsalikian E, Kollman C, Tamborlane WB et al. Prevention of hypoglycemia during exercise in children with type 1 diabetes by suspending basal insulin. Diabetes Care 2006: 29: 2200-2204.

57. Jungheim K, Koschinsky T. Glucose monitoring at the arm: risky delays of hypoglycemia and hyperglycemia detection. Diabetes Care 2002: 25: 956-960.

58. Lucidarme N, Alberti C, Zaccaria I, Claude E, Tubiana-Rufi N. Alternate-site testing is reliable in children and adolescents with type 1 diabetes, except at the forearm for hypoglycemia detection. Diabetes Care 2005: 28: 710-711.

59. Bergenstal R, Pearson J, Cembrowski GS, Bina D, DAvidson J, List S. Identifying variables associated with inaccurate self-monitoring of blood glucose: proposed guidelines to improve accuracy. Diabetes Educ 2000: 26: $981-989$.

60. Tsalikian E, Mauras N, Beck RW et al. Impact of exercise on overnight glycemic control in children with type 1 diabetes mellitus. J Pediatr 2005: 147: 528-534.

61. Tansey MJ, Tsalikian E, Beck RW et al. The effects of aerobic exercise on glucose and counterregulatory hormone concentrations in children with type 1 diabetes. Diabetes Care 2006: 29: 20-25.

62. Hermansson G, Ludvigsson J, Larsson Y. Home blood glucose monitoring in diabetic children and adolescents. A 3-year feasibility study. Acta Paediatr Scand 1986: 75: 98-105.

63. Bergenstal RM, Klonoff DC, Garg SK et al. Threshold-based insulin-pump interruption for reduction of hypoglycemia. N Engl J Med 2013: 369: 224-232.

64. Maahs DM, Calhoun P, Buckingham BA et al. A randomized trial of a home system to reduce nocturnal hypoglycemia in type 1 diabetes. Diabetes Care 2014: 37: 1885-1891.

65. Leelarathna L, Little SA, Walkinshaw E et al. Restoration of self-awareness of hypoglycemia in adults with long-standing type 1 diabetes: hyperinsulinemic-hypoglycemic clamp substudy results from the HypoCOMPaSS trial. Diabetes Care 2013: 36: 4063-4070.

66. Hovorka R. Closed-loop insulin delivery: from bench to clinical practive. Nat Rev Endocrinol 2011: 7: 385-395.

67. Choudhary P, Ramasamy S, Green L et al. Realtime continuous glucose monitoring significantly reduces severe hypoglycemia in hypoglycemiaunaware patients with type 1 diabetes. Diabetes Care 2013: 36: 4160-4162.

68. Buckingham B, Chase HP, Dassau E et al. Prevention of nocturnal hypoglycemia using predictive alarm algorithms and insulin pump suspension. Diabetes Care 2010: 33: 1013-1017.

69. Sparacino G, Zanderigo F, Corazza S, Maran A, Facchinetti A, Cobelli C. Glucose concentration can 
be predicted ahead in time from continuous glucose monitoring sensor time-series. IEEE Trans Biomed Eng 2007: 54: 931-937.

70. Mastrototaro JJ, Cooper KW, Soundararajan G, SANDERS JB, SHAH RV. Clinical experience with an integrated continuous glucose sensor/insulin pump platform: a feasibility study. Adv Ther 2006: 23: 725-732.

71. Chase HP, Kim LM, Owen SL et al. Continuous subcutaneous glucose monitoring in children with type 1 diabetes. Pediatrics 2001: 107: 222-226.

72. GARG S, ZisSer H, Schwartz S et al. Improvement in glycemic excursions with a transcutaneous, real-time continuous glucose sensor: a randomized controlled trial. Diabetes Care 2006: 29: 44-50.

73. Steck AK, Dong F, TaKi I, Hoffman M, Klingensmith GJ, Rewers MJ. Early hyperglycemia detected by continuous glucose monitoring in children at risk for type 1 diabetes. Diabetes Care 2014: 36: 4063-4070.

74. Borowiec M, Mysliwiec M, Fendler W et al. Phenotype variability and neonatal diabetes in a large family with heterozygous mutation of the glucokinase gene. Acta Diabetol 2011: 48: 203-208.

75. Jefferies C, Solomon M, Perlman K, Sweezey $\mathrm{N}$, Daneman D. Continuous glucose monitoring in children and adolescents with cystic fibrosis. J Pediatr 2005: 147: 396-398.

76. O'Riordan SM, Hindmarsh P, Hill NR et al. Validation of continuous glucose monitoring in children and adolescents with cystic fibrosis: a prospective cohort study. Diabetes Care 2009: 32: 1020-1022.

77. Deiss D, Bolinder J, Riveline JP et al. Improved glycemic control in poorly controlled patients with type 1 diabetes using real-time continuous glucose monitoring. Diabetes Care 2006: 29: 2730-2732.

78. Iscoe KE, Campbell JE, Jamnik V, Perkins BA, RIDDELL MC. Efficacy of continuous real-time blood glucose monitoring during and after prolonged highintensity cycling exercise: spinning with a continuous glucose monitoring system. Diabetes Technol Ther 2006: 8: 627-635.

79. Maia FF, Araujo LR. Accuracy, utility and complications of continuous glucose monitoring system (CGMS) in pediatric patients with type 1 diabetes. J Pediatr (Rio J) 2005: 81: 293-297.

80. Mozdzan M, Ruxer J, Loba J, Siejka A, MARKUSZEWSKI L. Safety of various methods of intense insulin therapy in hospital condition assessed by hypoglycemic episodes detected with the use of continuous glucose monitoring system. Adv Med Sci 2006: 51: 133-136.

81. Bergenstal RM, Tamborlane WV, Ahmann A et al. Effectiveness of sensor-augmented insulin-pump therapy in type 1 diabetes. New England Journal of Medicine 2010: 363: 311-320.

82. Beck RW, Buckingham B, Miller K et al. Factors predictive of use and of benefit from continuous glucose monitoring in type 1 diabetes. Diabetes Care 2009: 32: 1947-1953.

83. Weinzimer S, Xing D, Tansey M et al. Prolonged use of continuous glucose monitors in children with type 1 diabetes on continuous subcutaneous insulin infusion or intensive multiple-daily injection therapy. Pediatr Diabetes 2009: 10: 91-96.

84. JDRF CGM Study Group (Juvenile Diabetes Research Foundation Continuous Glucose Monitoring Study Group), Tamborlane WV, Beck RW et al. Continuous glucose monitoring and intensive treatment of type 1 diabetes. New England Journal of Medicine 2008: 359: 1464-1476.

85. Cemeroglu AP, Stone R, Kleis L, Racine MS, Pstellon DC, Wood MA. Use of a real-time continuous glucose monitoring system in children and young adults on insulin pump therapy: patients' and caregivers' perception of benefit. Pediatr Diabetes 2010: 11: 182-187.

86. BAtTelino T, KrZISNiK C. Incidence of type 1 diabetes mellitus in children in Slovenia during the years 1988-1995. Acta Diabetol 1998: 35: 112-114.

87. Phillip M, Battelino T, Atlas E et al. Nocturnal glucose control with an artificial pancreas at a diabetes camp. N Engl J Med 2013: 368: 824-833.

88. O'Grady MJ, Retterath AJ, KeEnan DB et al. The use of an automated, portable, glucose control system for overnight glucose control in adolescents and young adults with type 1 diabetes. Diabetes Care 2012: 35: 2182-2187.

89. Hovorka R, Elleri D, Thabit H et al. Overnight closed-loop insulin delivery in young people with type 1 diabetes: a free-living, randomized clinical trial. Diabetes Care 2014: 37: 1204-2011.

90. Cefalu WT, Tamborlane WV. The artificial pancreas: are we there yet? Diabetes Care 2014: 37: 1182-1183.

91. Laffel LMB, Wentzell K, Loughlin C, Tovar A, Moltz K, BrinK S. Sick day management using blood 3-hydroxybutyrate (3-OHB) compared with urine ketone monitoring reduces hospital visits in young people with T1DM: a randomized clinical trial. Diabet Med 2006: 23: 278-284.

92. Rewers A, McFanN K, Chase HP. Bedside monitoring of blood beta-hydroxybutyrate levels in the management of diabetic ketoacidosis in children. Diabetes Technol Ther 2006: 8: 671-676.

93. Klocker AA, Phelan H, Twigg SM, Craig ME. Blood $\beta$-hydroxybutyrate vs. urine acetoacetate testing for the prevention and management of ketoacidosis in type 1 diabetes: a systematic review. Diabet Med 2013: 30: $818-824$.

94. Rewers A, Chase HP, Mackenzie T et al. Predictors of acute complications in children with type 1 diabetes. JAMA 2002: 287: 2511-2518.

95. Taboulet $\mathrm{P}$, Deconinck $\mathrm{N}$, Thurel $\mathrm{A}$ et al. Correlation between urine ketones (acetoacetate) and capillary blood ketones (3-beta-hydroxybutyrate) in hyperglycaemic patients. Diabetes Metab 2007: 33: $135-139$.

96. TAHARA Y, Shima K. Kinetics of HbAlc, glycated albumin, and fructosamine and analysis of their weight functions against preceding plasma glucose level. Diabetes Care 1995: 18: 440-447.

97. Nathan DM, Kuenen J, Borg R, Zheng H, Schoenfeld D, Heine RJ. Translating the A1C assay into estimated average glucose values. Diabetes Care 2008: 31: 1473-1478.

98. Mosca A, Goodall I, Hoshino T et al. Global standardization of glycated hemoglobin measurement: 
the position of the IFCC Working Group. Clin Chem Lab Med 2007: 45: 1077-1080.

99. Report of the ADA/EAS/IDF Working Group of the HbA1c Assay, London, UK. Diabetologia 2014: 47: R53-R54.

100. Hoelzel W, Meidema K. Development of a reference system for the international standardization of HbA1c/glycohemoglobin determinates. J Int Fed Clin Chem 1996: 8: 62-67.

101. Kobold U, Jeppsson JO, Dulffer T, Finke A, Hoelzel W, Meidema K. Candidate reference methods for hemoglobin Alc based on peptide mapping. Clin Chem 1997: 43: 1944-1951.

102. Hoelzel W, Weykamp C, Jeppsson JO et al. IFCC reference system for measurement of hemoglobin A1c in human blood and the national standardization schemes in the United States, Japan, and Sweden: a method-comparison study. Clin Chem 2004: 50: $166-174$.

103. WeYKAMP C. HbA1c: a review of analytical and clinical aspects. Ann Lab Med 2013: 33: 393-400.

104. American Diabetes Association, European Association for the Study of Diabetes, International Federation of Clinical Chemistry and Laboratory Medicine, International Diabetes Federation. Consensus statement on the worldwide standardization of the hemoglobin A1C measurement. Diabetes Care 2007: 30: 2399-2400.

105. Tamborlane WV, Kollman C, Steffes MW et al. Comparison of fingerstick hemoglobin A1c levels assayed by DCA 2000 with the DCCT/EDIC central laboratory assay: results of a Diabetes Research in Children Network (DirecNet) Study. Pediatr Diabetes 2005: 6: 13-16.

106. Chiang JL, Kirkman MS, Laffel LMB, Peters AL, on behalf of the Type 1 Diabetes Sourcebook Authors. Type 1 diabetes through the life span: a position statement of the American Diabetes Association. Diabetes Care 2014: 37: 2034-2054.

107. Wood JR, Miller KM, MaAhs DM et al. Most youth with type 1 diabetes in the T1D Exchange Clinic Registry do not meet American Diabetes Association or International Society for Pediatric and Adolescent Diabetes clinical guidelines. Diabetes Care 2013: 36: 2035-2037.

108. Samualsson U, Hanberger L, Pundzuite-Lyck A, Akesson ElfVin K, ÖRtQvist E, SÄrnblad S, Miftaraj M. Yearly report. SWEDAIDKIDS. National quality register for children and adolescents with diabetes. Register Center Västra Götaland, Gothenburg, Sweden 2013 (available from https://swediabkids.ndr.nu/)

109. Gubitosi-KLug RA. The diabetes control and complications trial/epidemiology of diabetes interventions and complications study at 30 years: summary and future directions. Diabetes Care 2014: 37: 44-49.

110. Chase HP, Lockspeiser T, Peery B et al. The impact of the diabetes control and complications trial and humalog insulin on glycohemoglobin levels and severe hypoglycemia in type 1 diabetes. Diabetes Care 2001: 24: $430-434$.

111. Davis EA, Keating B, Byrne GC, Russell M, Jones TW. Impact of improved glycaemic control on rates of hypoglycaemia in insulin dependent diabetes mellitus. Arch Dis Child 1998: 78: 111-115.

112. NordFeldt S, Ludvigsson J. Adverse events in intensively treated children and adolescents with type 1 diabetes. Acta Paediatr 1999: 88: 1184-1193.

113. Mitrakou A, Ryan C, Veneman T et al. Hierarchy of glycemic thresholds for counterregulatory hormone secretion, symptoms, and cerebral dysfunction. Am J Physiol 1991: 260 (1 Pt 1): E67-E74.

114. Fanelli C, Pampanelli S, Epifano L et al. Relative roles of insulin and hypoglycaemia on induction of neuroendocrine responses to, symptoms of, and deterioration of cognitive function in hypoglycaemia in male and female humans. Diabetologia 1994: 37: 797-807.

115. Davis SN, Shavers C, Mosqueda-Garcia R, Costa F. Effects of differing antecedent hypoglycemia on subsequent counterregulation in normal humans. Diabetes 1997: 46: 1328-1335.

116. CRYER PE. Hypoglycemia: the limiting factor in glycaemic management of type I and type II diabetes. Diabetologia 2002: 45: 937-948.

117. Heller SR, CRYer PE. Reduced neuroendocrine and symptomatic responses to subsequent hypoglycemia after 1 episode of hypoglycemia in nondiabetic humans. Diabetes 1991: 40: 223-226.

118. Jones TW, Borg WP, Borg MA et al. Resistance to neuroglycopenia: an adaptive response during intensive insulin treatment of diabetes. J Clin Endocrinol Metab 1997: 82: 1713-1718.

119. Simonson DC, Tamborlane WV, DeFronzo RA, SHERWIN RS. Intensive insulin therapy reduces counterregulatory hormone responses to hypoglycemia in patients with type 1 diabetes. Ann Intern Med 1985: 103: $184-190$.

120. Cranston I, Lomas J, Maran A, Macdonald I, Amiel SA. Restoration of hypoglycaemia awareness in patients with long-duration insulin-dependent diabetes. Lancet 1994: 344: 283-287.

121. Cryer PE, Fisher JN, Shamoon H. Hypoglycemia. Diabetes Care 1994: 17: 734-755.

122. Bober E, Buyukgebiz A. Hypoglycemia and its effects on the brain in children with type 1 diabetes mellitus. Pediatr Endocrinol Rev 2005: 2: 378-382.

123. Desrocher M, Rovet J. Neurocognitive correlates of type 1 diabetes mellitus in chilhood. Child Neuropsychol 2004: 10: 36-52.

124. MaAhs DM, Hermann JM, DuBose SN et al. Contrasting the clinical care and outcomes of 2,622 children with type 1 diabetes less than 6 years of age in the United States T1D exchange and German/Austrian DPV registries. Diabetologia 2014.

125. Nathan DM, McGee P, Steffes MW, Lachin JM, DCCT/EDIC Research Group. Relationship of glycated albumin to blood glucose and HbA1c values and to retinopathy, nephropathy, and cardiovascular outcomes in the DCCT/EDIC study. Diabetes 2014: 63: $282-290$.

126. Selvin E, Rawlings AM, Grams M et al. Fructosamine and glycated albumin for risk stratification and prediction of incident diabetes and microvascular complications: a prospective cohort analysis of the Atherosclerosis Risk in Communities (ARIC) study. Lancet Diabetes Endocrinol 2014: 2: 279-288. 
Copyright of Pediatric Diabetes is the property of Wiley-Blackwell and its content may not be copied or emailed to multiple sites or posted to a listserv without the copyright holder's express written permission. However, users may print, download, or email articles for individual use. 